\title{
Equilibrium Study on the Ion Association of Monovalent and Divalent Naphtholsulfonates with Tetrabutylammonium Ion in an Aqueous Solution by Capillary Zone Electrophoresis
}

\author{
Toshio Takayanagi ${ }^{\dagger}$, Yoshitaka Ohba, Hiroko Haruki, Eiko Wada and Shoji Motomizu \\ Department of Chemistry, Faculty of Science, Okayama University, Tsushimanaka, Okayama 700-8530, Japan
}

\begin{abstract}
The ion-association properties of monovalent and divalent naphtholsulfonate ions were investigated with tetrabutylammonium ion $\left(\mathrm{TBA}^{+}\right)$as a pairing ion in an aqueous solution. The ion-association constants were obtained by analyzing the change in the electrophoretic mobility of naphtholsulfonate ions in the presence of $\mathrm{TBA}^{+}$by capillary zone electrophoresis; also, the contribution of a hydroxyl group to the ion associability of monovalent and divalent naphtholsulfonate ions, as well as the electrophoretic mobility of the ions, was investigated. The obtained ion-association constants indicate that the positional isomers possessing anionic groups at the $\beta$-position of the naphthalene ring are more associable with $\mathrm{TBA}^{+}$ than those at the $\alpha$-position, and that the ion associability of the divalent naphtholsulfonates is larger than those of the monovalent ones, except for 1-naphthol-2-sulfonate. The abnormal associability of 1-naphthol-2-sulfonate can be explained by a synergistic increase in the hydrophilicity of the divalent ion. The difference in the ion associability between the monovalent and divalent naphtholsulfonates, 0.16 in log unit on the average, was smaller than that between the naphthalenesulfonate and naphthalenedisulfonate ions, $0.30 \mathrm{log}$ unit on the average. The electrophoretic mobility of the naphtholsulfonate ions obtained in the absence of $\mathrm{TBA}^{+}$is compared with each other, and the contribution of the hydroxyl group is discussed on the basis of the hydration behavior of the naphtholsulfonates.
\end{abstract}

Keywords Ion association, aqueous solution, naphtholsulfonate, capillary zone electrophoresis, tetrabutylammonium ion

Capillary electrophoresis (CE) is a powerful separation system, especially for charged molecules. Since such anionic micelles as dodecyl sulfate micelles were used as a modifier of migrating buffers ${ }^{1}$, the usefulness of $\mathrm{CE}$ has been recognized rapidly and strongly in various fields concerning separation chemistry, and a number of electrically neutral substances have been separated favorably. Recently, various kinds of modifiers of migrating buffers have been used to improve the separability by $\mathrm{CE}$; they are, for example, cyclodextrin derivatives as a chiral recognition modifier ${ }^{2}$, cationic polyelectrolytes as an ion recognition ${ }^{3,4}$ and organic onium ions as an ion association., 5

In recent years, Takayanagi et al. reported on the usefulness of ion association in aqueous solution on the separation of positional isomers of organic anions by capillary zone electrophoresis (CZE). The main factors concerning the motive interactions for the ion association were found to be the hydrophobicity of pairing ions ${ }^{7,8}$ and the amount of charge. ${ }^{9}$ In previous studies $^{7-9}$, it was proved that CZE was a useful tool for the analysis of the equilibrium of ion-association reactions in aqueous solutions. In an equilibrium analysis by a CZE method, the electrophoretic mobility of a given UV-absorbing analyte ion was measured in the presence of large excess amounts of a pairing ion, such

$\doteqdot$ To whom correspondence sould be addressed. as quaternary ammonium ions, where the concentrations of the analyte ions were as low as $10^{-5} \mathrm{~mol} \mathrm{dm}^{-3}$. The unique advantages of the equilibrium analysis by the CZE method are as follows: (1) applicability to easy-to-precipitate ion associates; (2) no need to accurately know the concentrations of the analyte ions (the accurate mobility and the concentrations of pairing ions in the migrating solution are necessary for the determination of equilibrium constants); (3) the possibility of simultaneous measurements of the mobility of analyte ions (impurities existing in the analyte ions do not interfere with the determination); (4) an accurate analysis of the reaction of a very weak interaction. By using the CZE method, the ion-association constants of monovalent organic anions with monovalent organic cations were successfully determined for the first time. ${ }^{9}$

In the present study, the ion associability of eight kinds of naphtholsulfonate anions was examined using the tetrabutylammonium ion $\left(\mathrm{TBA}^{+}\right)$as a pairing cation. These anions exist as monovalent and/or divalent ions at a certain $\mathrm{pH}$ condition; also, the difference in the ion associability of the anions between the two ionic forms is of great interest with respect of the hydrophilicity of the anionic groups, the position of the ionic site and the separability by capillary zone electrophoresis. Furthermore, information concerning the contribution of a hydroxyl group to the ion associability is essentially important because the hydroxyl group is 
commonly present in organic compounds, especially in various kinds of biomolecules.

\section{Experimental}

\section{Apparatus and reagents}

The capillary electrophoresis system and silica capillary used in this work were the same as those used in previous work. ${ }^{9}$ Eight kinds of positional isomers of $m$-naphthol- $n$-sulfonate (abbreviated as $m \mathrm{~N} n \mathrm{~S} ; 1 \mathrm{~N} 2 \mathrm{~S}$, $1 \mathrm{~N} 3 \mathrm{~S}, 1 \mathrm{~N} 4 \mathrm{~S}, 1 \mathrm{~N} 5 \mathrm{~S}, 1 \mathrm{~N} 8 \mathrm{~S}, 2 \mathrm{~N} 6 \mathrm{~S}, 2 \mathrm{~N} 7 \mathrm{~S}$ and $2 \mathrm{~N} 8 \mathrm{~S}$ ), where $m$ and $n$ are the number of positions in the naphthalene ring, were purchased from Tokyo Kasei Kogyo. They were all sodium salts and were used as analyte anions without further purification. The protonated and deprotonated forms of the hydroxyl group of analyte anions were represented as $\mathrm{HA}^{-}$and $\mathrm{A}^{2-}$, respectively. The salts of the analyte anions were dissolved in purified water. Migrating buffer solutions containing 2morpholinoethanesulfonic acid (MES)-NaOH ( $\mathrm{pH}$ 6.0), $\mathrm{KH}_{2} \mathrm{PO}_{4}-\mathrm{Na}_{2} \mathrm{HPO}_{4}(\mathrm{pH} 6.0), \mathrm{Na}_{2} \mathrm{~B}_{4} \mathrm{O}_{7}-\mathrm{HCl}$ or- $\mathrm{NaOH}$ (pH $8-10)$ and $\mathrm{NaOH}(\mathrm{pH} 12.0)$ were used. Tetra-

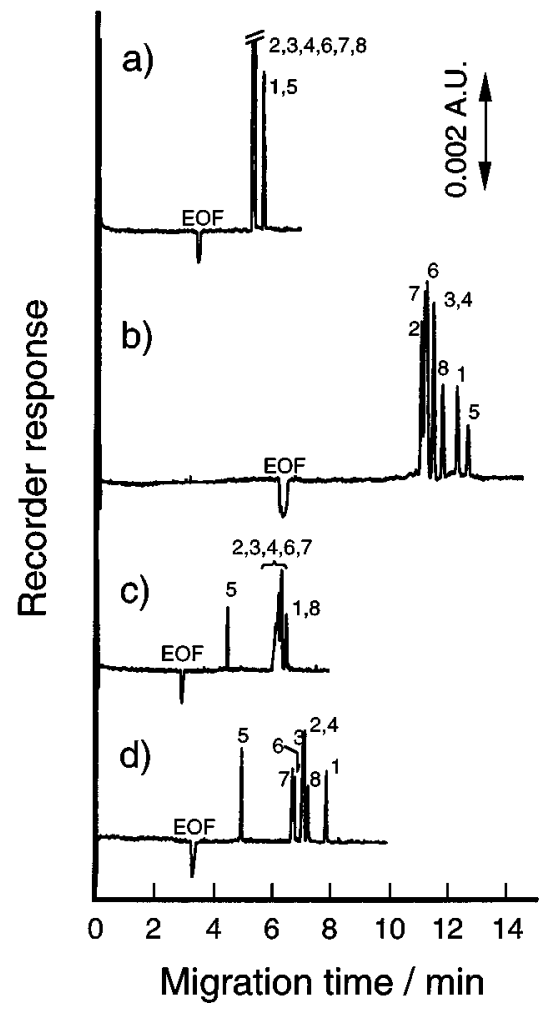

Fig. 1 Typical electropherograms of naphtholsulfonate anions in the absence and presence of $\mathrm{TBA}^{+}$. Sample solution: eight kinds of $2 \times 10^{-5} \mathrm{~mol} \mathrm{dm}^{-3}$ anions $+3 \%(\mathrm{v} / \mathrm{v})$ ethanol. Migrating solution: a) $1 \times 10^{-2} \mathrm{~mol} \mathrm{dm}^{-3}$ MES buffer (pH 6.0); b) $1 \times 10^{-2}$ mol dm ${ }^{-3}$ MES buffer (pH 6.0) $+2 \times 10^{-2} \mathrm{~mol} \mathrm{dm}^{-3} \mathrm{TBA}^{+} \cdot \mathrm{Br} ; \mathrm{c}$ ) $1 \times 10^{-2} \mathrm{~mol} \mathrm{dm}{ }^{-3} \mathrm{NaOH}(\mathrm{pH} 12.0)$; d) $1 \times 10^{-2} \mathrm{~mol} \mathrm{dm}^{-3} \mathrm{NaOH}$ $(\mathrm{pH} 12.0)+1 \times 10^{-2} \mathrm{~mol} \mathrm{dm}^{-3} \mathrm{TBA}^{+} \cdot \mathrm{Br}^{-}$. CE conditions are cited in the text. $1,1 \mathrm{~N} 2 \mathrm{~S} ; 2,1 \mathrm{~N} 3 \mathrm{~S} ; 3,1 \mathrm{~N} 4 \mathrm{~S} ; 4,1 \mathrm{~N} 5 \mathrm{~S} ; 5$, 1N8S; 6, 2N6S; 7, 2N7S; 8, 2N8S. butylammonium ion (bromide salt, $\mathrm{TBA}^{+} \cdot \mathrm{Br}^{-}$) was used as an ion-association reagent, which was added to the migrating solutions.

\section{Procedure for the CZE measurement}

A migrating solution was filled in a cathodic and anodic reservoir, as well as in a capillary. A sample solution containing $2 \times 10^{-5} \mathrm{~mol} \mathrm{dm}^{-3}$ of a certain analyte anion was introduced from the anodic end of the capillary for $3 \mathrm{~s}$ (injection volume: about $9 \mathrm{nl}$ ). A voltage of $20 \mathrm{kV}$ was then applied, and electrophoresis was started. The electric currents were less than $20 \mu \mathrm{A}$ under any of the migrating conditions examined, and it was suitable for the present purpose. All analyte anions were photometrically detected at $225 \mathrm{~nm}$. The electroosmotic flow (EOF) was monitored by detecting the peak of ethanol $(3 \%(\mathrm{v} / \mathrm{v}))$ added to the sample solution. The electrophoretic mobility, as well as the velocity of EOF, was calculated in an ordinary manner. During the experiment, the capillary was held in a thermostated compartment kept at $35^{\circ} \mathrm{C}$.

\section{Results and Discussion}

Separation behavior of analyte anions with and without an ion-association reagent

Electropherograms of the analyte anions are shown in Fig. 1. Since the analyte anions examined were positional isomers, the mutual separation of each anion was not sufficient when the migrating solution contained only buffer components, as can be seen from Figs. 1 (a) and (c). The separation of the positional isomers was well improved when $\mathrm{TBA}^{+}$was used as a pairing ion under both $\mathrm{pH}$ conditions of 6.0 and 12.0 \{Figs. 1 (b) and (d)\}.

\section{Acid-dissociation property of naphtholsulfonates}

The acid-dissociation constants $\left(\mathrm{p} K_{\mathrm{a}}\right)$ of naphtholsulfonates were examined by measuring the electrophoretic mobility of the analyte anions using various migrating buffers $\left(\mathrm{Na}_{2} \mathrm{~B}_{4} \mathrm{O}_{7}-\mathrm{HCl}\right.$ or $\left.-\mathrm{NaOH}\right)$ at different pHs. Equilibrium analyses gave the acid dissociation constants; the obtained $\mathrm{p} K_{\mathrm{a}}$ values are summarized in Table 1. Most of the obtained values agree well with the reported values. ${ }^{10,11}$ In the case of $1 \mathrm{~N} 8 \mathrm{~S}$, the mobility change with changing $\mathrm{pH}$ was too small to determine the $\mathrm{p} K_{\mathrm{a}}$ value, because its $\mathrm{p} K_{\mathrm{a}}$ was too high and about 13. The acid-dissociation constants obtained in this work seem to be more reliable than the reported values, because the present method is not interfered from UVabsorbing impurities probably included in the analyte anions.

Mobility changes of naphtholsulfonates present as monovalent anions by the addition of an ion-association reagent

When the $\mathrm{pH}$ of the migrating solution was 6.0, all of the naphtholsulfonate ions existed as monovalent 
Table 1 Equilibrium constants and electrophoretic mobilities obtained in this study

\begin{tabular}{|c|c|c|c|c|c|c|}
\hline \multirow{2}{*}{ Analyte anions ${ }^{\mathrm{a}}$} & \multicolumn{3}{|c|}{ Equilibrium constant } & \multicolumn{3}{|c|}{ Electrophoretic mobility $/ 10^{-4} \mathrm{~cm}^{2} \mathrm{~V}^{-1} \mathrm{~s}^{-1}$} \\
\hline & $\mathrm{p} K_{\mathrm{a}}$ & $\log K_{\text {ass, } \mathrm{HA}^{\mathrm{b}}}$ & $\log K_{\text {ass, } \mathrm{A}}{ }^{\mathrm{b}}$ & $-\mu_{\mathrm{ep}, \mathrm{HA}}$ & $-\mu_{\mathrm{ep}, \mathrm{A}}$ & $-\mu_{\mathrm{ePIA}, \mathrm{A}}$ \\
\hline $1 \mathrm{~N} 2 \mathrm{~S}$ & $9.50(9.47)^{\mathrm{d}}$ & $1.30 \pm 0.08$ & $1.04 \pm 0.11$ & $3.18(3.21)$ & $5.59(5.56)$ & 1.79 \\
\hline $1 \mathrm{~N} 3 \mathrm{~S}$ & $8.53(8.7)^{\mathrm{e}}$ & $1.35 \pm 0.07$ & $1.42 \pm 0.14$ & $2.89(2.90)$ & $5.27(5.27)$ & 1.64 \\
\hline $1 \mathrm{~N} 4 \mathrm{~S}$ & $8.11(8.2)^{\mathrm{e}}$ & $1.22 \pm 0.10$ & $1.28 \pm 0.16$ & $2.82(2.84)$ & $5.37(5.32)$ & 1.76 \\
\hline $1 \mathrm{~N} 5 \mathrm{~S}$ & $8.87(9.11)^{\mathrm{d}}$ & $1.24 \pm 0.09$ & $1.37 \pm 0.14$ & $2.86(2.90)$ & $5.16(5.20)$ & 1.60 \\
\hline $1 \mathrm{~N} 8 \mathrm{~S}$ & $-^{f}(13.02)^{d}$ & $1.20 \pm 0.10$ & $-^{f}$ & $3.14(3.12)$ & $-\mathrm{f}$ & $-^{\mathrm{f}}$ \\
\hline $2 \mathrm{~N} 6 \mathrm{~S}$ & $9.02(9.14)^{\mathrm{d}}$ & $1.29 \pm 0.09$ & $1.59 \pm 0.12$ & $2.85(2.86)$ & $5.23(5.19)$ & 1.58 \\
\hline $2 \mathrm{~N} 7 \mathrm{~S}$ & $9.17(9.35)^{\mathrm{d}}$ & $1.32 \pm 0.06$ & $1.59 \pm 0.16$ & $2.90(2.91)$ & $5.22(5.14)$ & 1.57 \\
\hline $2 \mathrm{~N} 8 \mathrm{~S}$ & $9.50(9.48)^{d}$ & $1.19 \pm 0.09$ & $1.30 \pm 0.17$ & $2.87(2.89)$ & $5.52(5.58)$ & 1.70 \\
\hline $1-\mathrm{NS}$ & & $1.08 \pm 0.11^{\mathrm{g}}$ & & $3.49^{\mathrm{h}}$ & & \\
\hline 2-NS & & $1.16 \pm 0.05^{\mathrm{g}}$ & & $3.52^{\mathrm{h}}$ & & \\
\hline $1-\mathrm{NO}$ & & $0.92 \pm 0.11^{\mathrm{g}}$ & & $3.38^{\mathrm{h}}$ & & \\
\hline $2-\mathrm{NO}$ & & $1.00 \pm 0.12^{\mathrm{g}}$ & & $3.28^{\mathrm{h}}$ & & \\
\hline $1,5-\mathrm{NDS}$ & & & $1.39 \pm 0.07^{\mathrm{i}}$ & & $5.01^{\mathrm{j}}$ & $2.07^{\mathrm{j}}$ \\
\hline 2,6-NDS & & & $1.44 \pm 0.07^{\mathrm{i}}$ & & $5.02^{\mathrm{j}}$ & $2.08^{\mathrm{j}}$ \\
\hline
\end{tabular}

a. NS, naphthalenesulfonate ion; NO, naphtholate ion; NDS, naphthalenedisulfonate ion. b. Error: $3 \sigma$. c. Calculated values. Values in parentheses are experimentally obtained values. d. Values in parentheses are reported values (ref. 10). e. Values in parentheses are reported values (ref. 11). f. Not determined. g. Values correspond to the $1: 1$ ion associate, which were cited from ref. 9 . h. Values of $-\mu_{\mathrm{ep}}$ of monovalent anions (ref. 9). i. Values correspond to the $1: 1$ ion associate, which were cited from ref. 8 . j. Ref. 8.

anions, as could be expected from the $\mathrm{p} K_{\mathrm{a}}$ values given in Table 1. The effect of the concentrations of $\mathrm{TBA}^{+}$ was examined using the migrating solution adjusted to pH 6.0 with the MES-NaOH buffer. The change in the apparent electrophoretic mobility $\left(-\mu_{\mathrm{ep}, \mathrm{HA}}{ }^{\prime}\right)$ is shown in Fig. 2. The electrophoretic mobility of monovalent anions $\left(-\mu_{\mathrm{ep}, \mathrm{HA}}\right)$ is also summarized in Table 1 . As can be seen from Table 1 , the values of $-\mu_{\mathrm{ep}, \mathrm{HA}}$ are smaller than those of monovalent naphthalenesulfonate (NS) and naphtholate (NO) ions, and the decreases in the mobility are much larger than those expected from the increase in the molecular weight of $\mathrm{HA}^{-}$. The electrophoretic measurement provides information about the hydration of analyte ions; that is, the hydrated ion increases its apparent molecular mass, which reduces its electrophoretic mobility. Considering the $-\mu_{\mathrm{ep}, \mathrm{HA}}$ values obtained in this work, these results indicate that the hydroxyl group in $\mathrm{HA}^{-}$is greatly hydrated. It is also noticed that the $-\mu_{\mathrm{ep}, \mathrm{HA}}$ values of $1 \mathrm{~N} 2 \mathrm{~S}$ and $1 \mathrm{~N} 8 \mathrm{~S}$ are larger than those of other isomers. These results suggest that the hydration behavior of these two anions is different from that of the other isomers. Since the sulfonate group of $1 \mathrm{~N} 8 \mathrm{~S}$ is placed near to the hydroxyl group, hydrogen bonding occurs between the $-\mathrm{SO}_{3}{ }^{-}$and $-\mathrm{OH}$ groups. As a result, the number of hydrated water molecule are fewer than those in other naphtholsulfonate anions. The extremely higher $\mathrm{p} K_{\mathrm{a}}$ value of $1 \mathrm{~N} 8 \mathrm{~S}$ also indicates the presence of hydrogen bonding. In $1 \mathrm{~N} 2 \mathrm{~S}$, since the hydroxyl group is present at a position adjacent to the sulfonate group, hydrogen bonding can not be formed between the hydroxyl and sulfonate groups. However, hydration around these adjacent groups is decreased due to a steric hindrance.

The values of $-\mu_{\mathrm{ep}, \mathrm{HA}}$ ' decreased with increasing the concentrations of $\mathrm{TBA}^{+}$added to the migrating solutions. Such decrease is correlated to the ion-association reaction of the analyte anions with $\mathrm{TBA}^{+}$, which is discussed in a later section.

The magnitude of the decrease in $-\mu_{\mathrm{ep}, \mathrm{HA}}{ }^{\prime}$ was almost identical when a phosphate buffer $(\mathrm{pH}$ 6.0) was used instead of the MES-NaOH buffer. This result indicates that the buffer components do not interfere with the ion-association reaction in an aqueous solution under

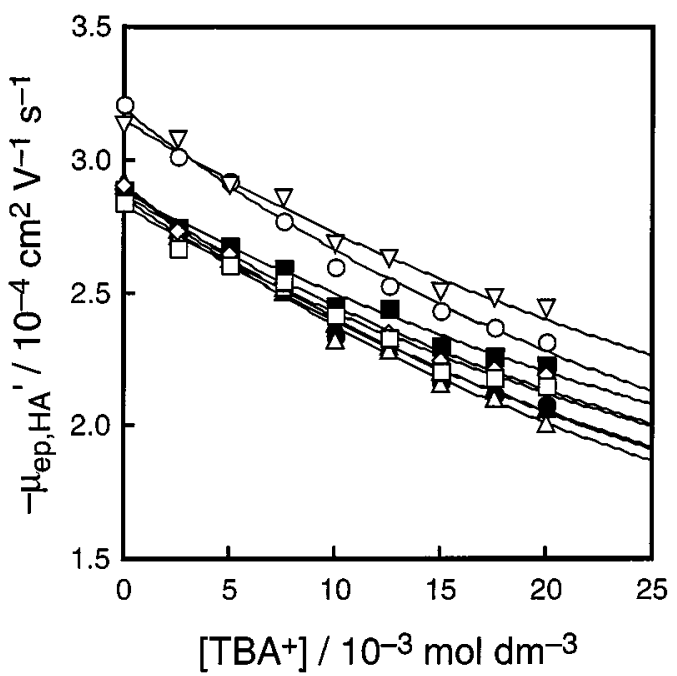

Fig. 2 Change in the electrophoretic mobility of $\mathrm{HA}^{-}$with an increase in the $\mathrm{TBA}^{+}$concentrations. Migrating solution: $1 \times 10^{-2} \mathrm{~mol} \mathrm{dm}^{-3} \mathrm{MES}-\mathrm{NaOH}(\mathrm{pH} 6.0)+(0-2) \times 10^{-2} \mathrm{~mol} \mathrm{dm}^{-3}$ $\mathrm{TBA}^{+} \cdot \mathrm{Br}^{-}$. Sample solution and $\mathrm{CE}$ conditions are the same as in Fig. 1. ०, 1N2S; $\triangle, 1 \mathrm{~N} 3 \mathrm{~S} ; \square, 1 \mathrm{~N} 4 \mathrm{~S} ; \diamond, 1 \mathrm{~N} 5 \mathrm{~S} ; \nabla$, $1 \mathrm{~N} 8 \mathrm{~S} ; \bullet, 2 \mathrm{~N} 6 \mathrm{~S} ; \bullet, 2 \mathrm{~N} 7 \mathrm{~S} ; \boldsymbol{\square}, 2 \mathrm{~N} 8 \mathrm{~S}$. 
the present experimental conditions.

Mobility changes of naphtholsulfonates present as divalent anions by the addition of an ion-association reagent

When $0.01 \mathrm{~mol} \mathrm{dm}^{-3} \mathrm{NaOH}$ was used as a migrating buffer, the analyte anions, except for $1 \mathrm{~N} 8 \mathrm{~S}$, existed as divalent anions, as expected from the $\mathrm{p} K_{\mathrm{a}}$ values. The electrophoretic mobility of divalent anions $\left(-\mu_{\mathrm{ep}, \mathrm{A}}\right)$ obtained at a pH of about 12 is summarized in Table 1 , from which it can be seen that the values of $-\mu_{\mathrm{ep}, \mathrm{A}}$ are larger than those present in the forms of the monovalent anions, $-\mu_{\mathrm{ep}, \mathrm{HA}}$. This is quite reasonable, because the charges of the anions increased from -1 to -2 . The values of $-\mu_{\mathrm{ep}, \mathrm{A}}$ of the divalent naphtholsulfonate anions are larger than those of the naphthalenedisulfonate (NDS) ions. This is probably because the molecular weight of the naphtholsulfonate ions is smaller than that of the NDS ions. The separability of the divalent isomers was slightly improved, even in the absence of $\mathrm{TBA}^{+}$, compared with that of monovalent isomers, as can be seen from the electropherogram in Fig. 1 (c). This suggests that the difference in the number of hydrated water molecules among the isomers increased when the charge changed from monovalence to divalence. In $1 \mathrm{~N} 8 \mathrm{~S}$, the migrating time was very short compared to that of the other isomers, as can be seen in Fig. 1 (c). This is quite reasonable because most of the anions of $1 \mathrm{~N} 8 \mathrm{~S}$ exist in the monovalent form at 0.01 mol dm${ }^{-3} \mathrm{NaOH}$, and the mobility is much smaller than that of the other isomers. The hydration behavior or difference in the number of hydrated water molecules of analyte ions is also discussed in later sections concerning the electrophoretic mobility.

The apparent electrophoretic mobility of the divalent anions $\left(-\mu_{\mathrm{ep}, \mathrm{A}}{ }^{\prime}\right)$ changed upon the addition of $\mathrm{TBA}^{+}$in the migrating solution, as shown in Fig. 3. The decrease in $-\mu_{\mathrm{ep}, \mathrm{A}^{\prime}}$ of divalent $1 \mathrm{~N} 2 \mathrm{~S}$ with increasing $\mathrm{TBA}^{+}$concentration was very small compared with that of other divalent isomers. A similar phenomenon was observed for the 1,2-phthalate ion. ${ }^{8}$ This phenomenon is attributed to the lower hydrophobicity in adjacent anionic groups than that in apart anionic groups.

\section{Ion-association constants}

The decrease in the apparent electrophoretic mobility of analyte anions can be correlated to the ion associability in an aqueous solution between $\mathrm{TBA}^{+}$and the analyte anions. The following ion-association reactions occur in the anions, $\mathrm{HA}^{-}$and $\mathrm{A}^{2-}$ :

$$
\begin{aligned}
& \mathrm{TBA}^{+}+\mathrm{HA}^{-} \stackrel{K \text { ass,HA }}{\rightleftharpoons} \mathrm{TBA}^{+} \cdot \mathrm{HA}^{-}, \\
& \mathrm{TBA}^{+}+\mathrm{A}^{2-} \stackrel{K_{\text {ass, }, \mathrm{A}}}{\rightleftharpoons} \mathrm{TBA}^{+} \cdot \mathrm{A}^{2-} .
\end{aligned}
$$

The corresponding constants, $K_{\text {ass,HA }}$ and $K_{\text {ass,A, }}$ can be represented as

$$
\begin{aligned}
& K_{\text {ass, } \mathrm{HA}}=\frac{\left[\mathrm{TBA}^{+} \cdot \mathrm{HA}^{-}\right]}{\left[\mathrm{TBA}^{+}\right]\left[\mathrm{HA}^{-}\right]}, \\
& K_{\text {ass, }}=\frac{\left[\mathrm{TBA}^{+} \cdot \mathrm{A}^{2-}\right]}{\left[\mathrm{TBA}^{+}\right]\left[\mathrm{A}^{2-}\right]} .
\end{aligned}
$$

The apparent electrophoretic mobility of $\mathrm{HA}^{-}$or $\mathrm{A}^{2-}$, $-\mu_{\mathrm{ep}, \mathrm{HA}}{ }^{\prime}$ and $-\mu_{\mathrm{ep}, \mathrm{A}^{\prime}}$, respectively, can be expressed as

$$
\begin{aligned}
-\mu_{\mathrm{ep}, \mathrm{HA}}{ }^{\prime}= & \frac{1}{1+K_{\mathrm{ass}, \mathrm{HA}}\left[\mathrm{TBA}^{+}\right]} \times\left(-\mu_{\mathrm{ep}, \mathrm{HA}}\right) \\
& +\frac{K_{\mathrm{ass}, \mathrm{HA}}\left[\mathrm{TBA}^{+}\right]}{1+K_{\mathrm{ass}, \mathrm{HA}}\left[\mathrm{TBA}^{+}\right]} \times\left(-\mu_{\mathrm{epIA}, \mathrm{HA}}\right), \\
-\mu_{\mathrm{ep}, \mathrm{A}}{ }^{\prime}= & \frac{1}{1+K_{\mathrm{ass}, \mathrm{A}}\left[\mathrm{TBA}^{+}\right]} \times\left(-\mu_{\mathrm{ep}, \mathrm{A}}\right) \\
& +\frac{K_{\mathrm{ass}, \mathrm{A}}\left[\mathrm{TBA}^{+}\right]}{1+K_{\mathrm{ass}, \mathrm{A}}\left[\mathrm{TBA}^{+}\right]} \times\left(-\mu_{\mathrm{epIA}, \mathrm{A}}\right),
\end{aligned}
$$

where $-\mu_{\text {epIA,HA }}$ and $-\mu_{\text {epIA,A }}$ are the electrophoretic mobility of the ion associates, $\mathrm{TBA}^{+} \cdot \mathrm{HA}^{-}$and $\mathrm{TBA}^{+} \cdot \mathrm{A}^{2-}$, respectively. To obtain the ion-association constants, a non-linear least-squares method was used in a similar manner as in previous works. ${ }^{8,9}$ In a calculation of $K_{\mathrm{ass}, \mathrm{HA}}$, the ion associate, $\mathrm{TBA}^{+} \cdot \mathrm{HA}^{-}$, was expected to be electrically neutral, and a value of zero was used for the value of $-\mu_{\mathrm{epIA}, \mathrm{HA}}$. In a calculation of $K_{\text {ass,A }}$, the values of $-\mu_{\text {epIA,A }}$ were also optimized, as well as $-\mu_{\mathrm{ep}, \mathrm{A}}$; they are summarized in Table 1 . The ionassociation constants obtained in this study are also summarized in Table 1.

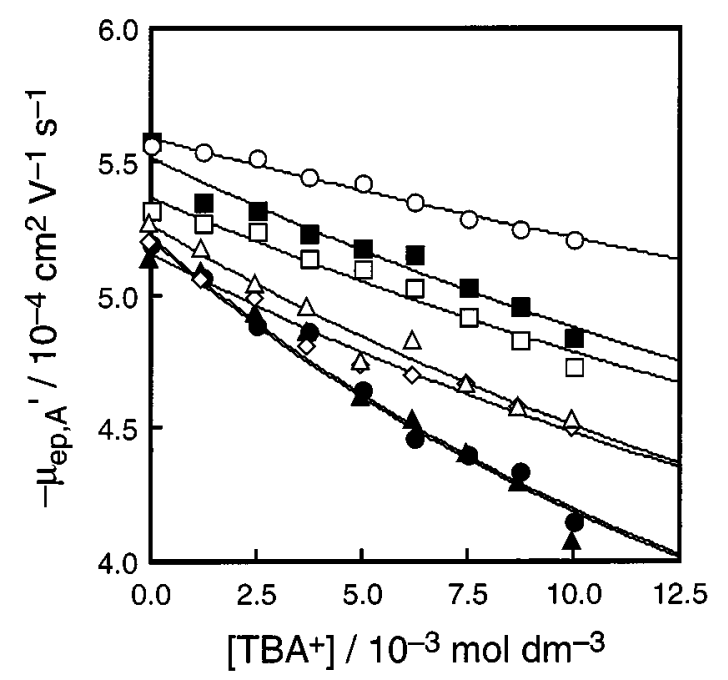

Fig. 3 Change in the electrophoretic mobility of $\mathrm{A}^{2-}$ with an increase in the $\mathrm{TBA}^{+}$concentrations. Migrating solution: $1 \times 10^{-2} \mathrm{~mol} \mathrm{dm}^{-3} \mathrm{NaOH}(\mathrm{pH} 12.0)+(0-1) \times 10^{-2} \mathrm{~mol} \mathrm{dm}^{-3}$ $\mathrm{TBA}^{+} \cdot \mathrm{Br}^{-}$. Sample solution and $\mathrm{CE}$ conditions are the same as in Fig. 1. $0,1 \mathrm{~N} 2 \mathrm{~S} ; \triangle, 1 \mathrm{~N} 3 \mathrm{~S} ; \square, 1 \mathrm{~N} 4 \mathrm{~S} ; \diamond, 1 \mathrm{~N} 5 \mathrm{~S}$; 2N6S;, $2 \mathrm{~N} 7 \mathrm{~S} ; \boldsymbol{-}, 2 \mathrm{~N} 8 \mathrm{~S}$. 
Comparison of the ion associability of naphtholsulfonate ions

It can be seen from the ion-association constants given in Table 1 that the ion associability of the monovalent naphtholsulfonate ions with $\mathrm{TBA}^{+}$is larger than that of 1- and 2-naphthalenesulfonates (1- and 2-NS). ${ }^{9}$ The increase in the ion associability of naphtholsulfonates can be attributed to the hydroxyl group introduced into the naphthalenesulfonates. In naphtholsulfonates, the hydroxyl group acts as an electron-donating group; therefore, the electron density of the sulfonate group is increased and the ion associability of monovalent naphtholsulfonates is large compared with that of the naphthalenesulfonates.

The ion associability of the each analyte anion was compared with each other from the view point of the position of the anionic groups. In the monovalent form, the values of $K_{\text {ass,HA }}$ were larger when a sulfonate group was present at the $\beta$-position of the naphthalene ring; that is, the values of $1 \mathrm{~N} 2 \mathrm{~S}, 1 \mathrm{~N} 3 \mathrm{~S}, 2 \mathrm{~N} 6 \mathrm{~S}$ and 2N7S (average $\log K_{\text {ass }, \mathrm{HA}}$ with \pm deviation: $1.32 \pm 0.08$ ) were larger than those of $1 \mathrm{~N} 4 \mathrm{~S}, 1 \mathrm{~N} 5 \mathrm{~S}, 1 \mathrm{~N} 8 \mathrm{~S}$ and $2 \mathrm{~N} 8 \mathrm{~S}$ (average $\log K_{\text {ass }, \mathrm{HA}}$ with \pm deviation: $1.21 \pm 0.10$ ). Similarly, in the case of the divalent form, the order of the ion associability was $2 \mathrm{~N} 6 \mathrm{~S}$ and $2 \mathrm{~N} 7 \mathrm{~S}(\beta, \beta)>$ $1 \mathrm{~N} 3 \mathrm{~S}$ and $2 \mathrm{~N} 8 \mathrm{~S}(\alpha, \beta$ or $\beta, \alpha)>1 \mathrm{~N} 4 \mathrm{~S}$ and $1 \mathrm{~N} 5 \mathrm{~S}(\alpha$, $\alpha)$. These results are in good agreement with the order of the basicity, $\beta$-position $>\alpha$-position, reported in a previous study. ${ }^{9}$

In a comparison of the monovalent and divalent naphtholsulfonates, the ion associability of the divalent anions was larger than that of the monovalent ones, except for $1 \mathrm{~N} 2 \mathrm{~S}$. This increase in the ion associability is attributed to an increase in the charge. However, the difference in the ion-association constants between the monovalent and divalent ions was about 0.16 in $\log$ unit on the average, which was smaller than the difference between the naphthalenesulfonate and naphthalenedisulfonate ions, 0.30 in log unit on the average. It is noticed that the increase in the ion associability of $1 \mathrm{~N} 2 \mathrm{~S}$ is reversed compared with the other isomers, even when the anion changes from the monovalent to the divalent form. This fact seems to be quite interesting with respect to the electrostatic interaction between a cation and an anion. The abnormal ion associability of the divalent $1 \mathrm{~N} 2 \mathrm{~S}$ can be explained as follows. When the two adjacent anionic groups are placed at a close position, the electron density around these anionic groups is higher synergistically, and therefore the hydrophilicity of the groups becomes larger. As a result, the hydration shell around the anionic groups becomes thicker than that of the other anions in which the two anionic groups were present apart. The increase in the thickness of the hydration shell results in a lowering of the hydrophobic ion association with $\mathrm{TBA}^{+}$. A similar phenomenon was observed previously: naphthalene-2,3-dicarboxylate and 1,2-phthalate were less associable with $\mathrm{TBA}^{+}$than other corresponding divalent anions. ${ }^{8}$

In conclusion, the ion-association constants of naphtholsulfonates with $\mathrm{TBA}^{+}$were successfully determined, and the ion associability and electrophoretic mobility of naphtholsulfonates could be reasonably explained on the basis of the number of charge, the positions of the anionic groups, and hydration behavior related to the electrophoretic mobility.

This study was supported by a Grant-in-Aid (No. 09440251) from the Ministry of Education, Science, Sports and Culture.

\section{References}

1. S. Terabe, K. Otsuka, K. Ichiwada, A. Tsuchiya and T. Ando, Anal. Chem., 56, 111 (1984).

2. S. Terabe, Y. Miyashita, O. Shibata, R. E. Barnhart, R. L. Alexander, G. D. Patterson, B. L. Karger, K. Hosoya and N. Tanaka, J. Chromatogr., 516, 23 (1990).

3. S. Terabe and T. Isemura, Anal. Chem., 62, 650 (1990).

4. C. Stathakis and R. M. Cassidy, Anal. Chem., 66, 2110 (1994).

5. N. Iki, H. Hoshino and T. Yotsuyanagi, J. Chromatogr. A, 652, 539 (1993).

6. S. Motomizu, M. Kuwabara and M. Oshima, Bunseki Kagaku, 43, 621 (1994).

7. T. Takayanagi and S. Motomizu, Chem. Lett., 1995, 593.

8. T. Takayanagi, E. Wada and S. Motomizu, Analyst [London], 122, 57 (1997).

9. T. Takayanagi, E. Wada and S. Motomizu, Bunseki Kagaku, 46, 467 (1997).

10. J. T. V. Gemert, Aust. J. Chem., 22, 1883 (1969).

11. H. Zollinger and W. Bücher, Helv. Chim. Acta, 33, 2002 (1950).

(Received August 11, 1997) (Accepted November 10, 1997) 